\title{
Development of a Patient-Centric Food Allergy Research Program: A Model for Action
}

To the Editor:

Attention to patient perspectives on healthcare and disease burden is the guiding principle of patient-centered outcomes research (1) and is an approach increasingly employed by researchers in allergic disease settings, such as asthma (2) and allergic rhinosinusitis (3) and urticaria (4). Because of the all-encompassing impact of food allergies on daily living, including social and economic effects, the food allergy context is especially suited for an approach to research designed to account for the lived experiences of food allergic patients and their families.

Despite recent advances in understanding the effects of food allergy on quality of life, gaps still exist in key areas like participation in clinical trials, access to safe foods and epinephrine and public understanding of food allergies (4- $\underline{5})$. Outcomes research offers the opportunity to examine the lives of those impacted by food allergies to determine the wide range of issues that are most important to those directly affected and to address these gaps $(5 \underline{6})$. The goal of this letter is to describe a model for engaging key stakeholders in the development of a patient-centric food allergy research agenda.

To address gaps in patient-centered food allergy outcomes research, Food Allergy Research \& Education (FARE) successfully competed for a Eugene Washington Engagement Award from the Patient-Centered Outcomes Research Institute (PCORI), and in May 2016, announced a two-year initiative entitled "Empowering Patient Partners and Key Stakeholders to Develop a Patient-Centric Food Allergy Research Program.” FARE created an Outcomes

This is the authors' manuscript of the work published in final form as:

Bute, J. J., Broome, S. B., Marcus, J. N., Mikulcik, S., \& Vickery, B. (2018). Development of a patient-centric food allergy research program: A model for action. Allergy, 73(7), 1551-1553. https://doi.org/10.1111/all.13452 
Research Advisory Board (ORAB) as a key component of this initiative to create a stakeholderdriven, outcomes-centered research agenda. A call for applications to the ORAB was announced in the FARE newsletter and via the FARE web site, and members were selected through a conflict-free vetting process.

The ORAB is comprised of individuals with an array of experiences, including individuals with food allergies; parents of children with food allergies, academic, communitybased, and industry researchers; and other stakeholders such as nurses, educators, advocates, health plan payers and pharmacy benefit managers. Select clinicians and researchers from the FARE Clinical Network also serve on the board. The 44 members are organized into four regional subgroups (Midwest, Northeast Mid-Atlantic, South and West), with each subgroup comprised of 10-12 members. The board was charged with working collectively to identify and prioritize a set of food allergy research initiatives informed by patient needs and experiences.

The ORAB began working in the summer of 2016 when each of the regional groups met in person (see Figure 1). Over the next seven months, the regional groups continued meeting online and via conference call, and communicating via email to narrow and define research priorities. The meetings allowed the board to stay-up-to-date on emerging findings regarding new discoveries about possible causes of food allergy, potential therapeutic developments, and FARE's work in education, awareness and advocacy. Each subgroup conducted an online survey of its members to prioritize a list of the most pressing patient-centered topic areas requiring greater attention from the research community.

In March of 2017, each regional subgroup drafted a white paper outlining the five to six priority areas identified in its online survey. For each topic area, subgroups identified the existing knowledge in that area (e.g. current science on the efficacy of oral immunotherapy); specific 
unanswered questions that influence the experiences of food allergic patients and families (e.g. the preponderance of false positives in the diagnostic process); gaps in adherence or data relating to the topic (e.g. evidence suggesting that many patients do not know how to correctly administer an epinephrine autoinjector); ideas for including patient input in future study designs; and suggestions for addressing underserved populations to reduce disparities in care. The four completed papers were then distributed to the entire national board and submitted to PCORI as part of FARE's first-year progress report.

In April 2017, the ORAB members met at FARE's Annual Research Retreat. Members engaged in day-long focus groups to prepare a national agenda of research priorities. The groups compared the four white papers and narrowed the list of priorities to five categories: therapeutic developments, diagnostic processes, improved product labeling, enhanced forms of epinephrine and quality of life issues involved in living with food allergies (see Table 1). Working in small groups organized by topic, the ORAB developed a short presentation for each topic area. During the second day of the Research Retreat, representatives from the ORAB presented these topic areas to an audience of FARE-funded and other leading scientists, as well as senior representatives from the National Institutes of Health, the Food and Drug Administration, and the pharmaceutical industry. In doing so, the ORAB highlighted the voices of adult allergy patients and caregivers of food-allergic children in describing the most pressing needs of the food allergy community. In addition, ORAB members, in conjunction with board advisers, conducted a pre and post survey before and after the research retreat to measure whether attendees' ratings of research priorities changed after hearing ORAB members present. These survey results have been submitted for presentation at an academic conference, and a full-length manuscript reporting the results is currently in draft. 
The ORAB serves as an exemplary model for involving key constituents in the development of a long-term research agenda. To date, the ORAB's research agenda has been presented at meetings of the American College of Asthma, Allergy and Immunology (ACAAI), the Patient Organization Committee of the European Academy of Allergy and Clinical Immunology (EAACI) and the first food allergy meeting hosted by the prestigious Gordon Research Conference. The work will be presented at additional conferences in the coming months.

We urge scientists and funding agencies committed to improving the lives of food allergy patients to account for the priorities identified by the ORAB in formulating research questions and making funding decisions. As emerging immunotherapies become more widely available, we must continue to draw on patient voices to understand patient and family perspectives on adherence to such therapies and the effects these therapies might have on the social and economic effects of food allergy (4- $\underline{5})$.

\section{References}

1. Wu AW, Kharrazi H, Boulware LE, Snyder CF. Measure once, cut twice—adding patient reported outcome measures to the electronic health record for comparative effectiveness research. J Clin Epidemiol 2013;66(8 Suppl):S12-S20.

2. Braido F, Baiardini I, Canonica GW. Patient-reported outcomes in asthma clinical trials. Curr Opin Pulm Med 2018;24(1):70-77.

3. Levy JM, Mace JC, Smith TL, Soler ZM. Influence of interpersonal traits on patient outcomes in the treatment of chronic rhinosinusitis. Int Forum Allergy Rhinol 2017;7(4):414-420. 
4. Maurer M, Metz M, Bindslev-Jensen C, Bousquet J, Canonica GW, Church MK, et al.

Definition, aims, and implementation of $\mathrm{GA}^{2} \mathrm{LEN}$ Urticaria Centers of Reference and

Excellence. Allergy 2016;71(8):1210-1218.

45. Polk BI, Dinakar C. Patient-centered outcomes in food allergy. Curr Allergy Asthma Rep 2017;17(6):39. doi:10.1007/s11882-017-0708-Z

56. Devine EB, Alfonso-Cristancho R, Devlin A, Edwards TC, Farrokhi ET, Kessler L, et al. A model for incorporating patient and stakeholder voices in a learning health care network:

Washington State's Comparative Effectiveness Research Translation Network. J Clin Epidemiol 2013;66(8 Supp1):S122-S129.

Jennifer J. Bute, PhD

IUPUI and ORAB Member

S. Brantlee Broome, PhD, MSN, RN

Medical University of South Carolina and ORAB Member

Jessica N. Marcus, BA

Independent Researcher and ORAB Member

Sandy Mikulcik, MA

Independent Researcher and ORAB Member

Brian Vickery, MD

University of North Carolina School of Medicine and ORAB Member

Funding Source: This project was funded by a Eugene Washington Engagement Award from the Patient-Centered Outcomes Research Institute (PCORI). 
Conflicts of Interest: None

The revision has been approved by all authors and meets the requirements for authorship for the journal. All authors contributed equally to writing the paper. This manuscript is an original work, has not been published previously and is not under review elsewhere. 